\title{
FAKTOR-FAKTOR YANG MEMPENGARUHI FIRM VALUE
}

\author{
Cynthia Ruana \\ Program Studi Magister Manajemen Universitas Tarumanagara \\ ruana.cynthia@gmail.com \\ Indra Widjaja \\ Program Studi Magister Manajemen Universitas Tarumanagara
}

Masuk : 30-11-2020, revisi : 21-12-2020 diterima untuk diterbitkan : 22-12-2020

\begin{abstract}
The purpose of this research is to examine what factors can trigger an increase in Firm Value. Therefore, this research cause Firm Value as a dependent variable and Leverage, Growth, Institutional Ownership, and Working Capital Turnover used as independent variables. Property and real estate companies listed in BEI period 2014-2018 used as a subject. The sample was determined by purposive sampling method of 38 companies. This research used Eviews program version 9.0. The results of the study indicate that Leverage and Institutional Ownership have a positive and significant impact on Firm Value, while Growth and Working Capital Turnover have a positive but insignificant impact on Firm Value.
\end{abstract}

Abstrak: Tujuan dari penelitian ini untuk menguji factor-faktor apa saja yang mampu menjadi pemicu peningkatan nilai perusahaan. Maka dari itu, penelitian menjadikan nilai perusahaan sebagai variabel dependen dan variabel independen yang digunakan yakni Leverage, Growth, Institutional Ownership dan Working Capital Turnover. Subjek yang digunakan yakni perusahaan property and real estate yang terdaftar di BEI periode 2014-2018. Pengambilan sampel menggunakan metode purposive sampling sebanyak 38 perusahaan. Penelitian ini menggunakan aplikasi pengolah data Eviews 9.0. Hasil dari penelitian menunjukkan bahwa Leverage dan Institutional Ownership berdampak positif dan signifikan terhadap nilai perusahaan sedangkan Growth dan Working Capital Turnover berdampak positif namun kurang signifikan terhadap nilai perusahaan.

Keywords: TB'Q, Leverage, Growth, Institutional Ownership, Working Capital Turnover

\section{PENDAHULUAN}

Nilai perusahaan menjadi sangat penting didalam kondisi ketika menginginkan investor untuk melirik dan mengenal lebih jauh mengenai perusahaan. Oleh karena itu perusahaan sendiri harus berloma-lomba untuk meningkatkan nilai perusahaan. Peningkatan nilai perusahaan mampu menaikkan minat investor untuk melakuikan investasi di perusahan. Investor akan lebih tertarik lagi apabila perusashaan mampu menghasilkan profit yang stabil. Penjualan yang dilakukan oleh perusahaan cukup memiliki peran penting untuk menggarab laba yang juga harus didukung dengan aktiva perushaan. Kenaikan akibat penjualan perusahaan mampu mempenaruhi nilai perusahaan. Pertumbuhan penjualan merupakan salah satu bukti yang menyatakan bahwa suatu perusahaan berkembang. Perusahaan yang memiliki pertumbuhan baik akan dinilai oleh investor bahwa perusahaan memiliki aspek yang menguntungkan perihal memperoleh return atas investasi yang dilakukan. Perihal meningkatkan nilai perusahaan, terdapat banyak permasalahan dalam perusahaan yang perlu untuk dituntaskan terlebih dahulu. Perbedaan kepentingan yang timbul dari masing-masing pihak. Perselisihan yang sering terjadi dalam perusahaan biasanya dikenal dengan sebutan Agency Conflict atau konflik keagenan. Agency Conflict terjadi dikarenakan perbedaan pendapat antara manajer dan pemilik perusahaan. Untuk mengatasinya, perlu dilakukannya 
pengawasan dalam perusahaan. Pengawasan dapat dilakukan dengan adanya monitoring yang dilakukan oleh investor-investor institutional.

\section{Tujuan Penelitian}

Peningkatan nilai perusahaan bisa dipengaruhi beberapa faktor baik sevara internal maupun eksternal perusahaan. Peningkatan nilai perusahaan menjadi hal utama yang harus dilakukan perusahaan agar mampu menarik minat investor dan mengembangkan perushaan menjadi lebih besar lagi. Nilai perusahaan juga harus selalu diperhatikan agar tidak memberikan kekecewaan kepada para investor yang telah menanamkan modal dengan harapan mendapatkan return sesuai dengan apa yang diharapakan. Oleh sebab itu penelitian ini mengambil beberapa faktor internal yang diduga mampu menjadi faktor pemicu peningkatan nilai perusahaan dan membuktikan secara empiris penaruh Leverage terhadap nilai perusahaan, Growth terhadap nilai perusahaan, Institutional Ownership terhadap nilai perusahaan dan Working Capital Turnover terhadap nilai perusahaan.

\section{TINJAUAN PUSTAKA}

Menurut Khaliq, et al., (2014:143), Leverage digunakan untuk mengetahui serta mengukur kondisi atau status suatu perusahan perihal dalam memenuhi kewajiban keuangan perusahaan itu sendiri. Brigham dan Houston (2006) mengatakan bahwa Leverage juga menjadi indikator untuk menunjukkan konsentrasi risiko yang diharus dihadapi oleh perusahaan, dimana semakin besar risiko yang dihadapi maka akan semakin besar juga tingkat ketidakpastian dalam memperolah laba di dalam perusahaan. Gitman \& Zutter (2012) mengatakan bahwa semakin tinggi Leverage akan menghasilkan tingkat return yang semakin tinggi namun tidak stabil hal ini dikarenakan Leverage mengacu terhadap biaya tetap atas pengembalian yang ingin dimiliki oleh pada pemegang saham.

Didalam perusahaaan hal yang mampu menunjukkan kesuksesan serta kelangsungkan hidup dari suatu perusahaan yakni penjualan. Dikatakan penjualan sebagai faktor penentu keberhasilan dikarenakan apabila suatu perusahaan mampu menunjukkan tingginya tingkat penjualan maka hal itu akan berdampak besar dalam hal meningkatkan laba perusahaan. Menurut Barton, et al. (1989), pertumbuhan pernjualan dapat dijadikan indikator keberhasilan investasi dapa periode sebelumnya dan dapat dijadikan sebagai alat memprediksi seberapa besar pertumbuhan dan permintaan dimasa yang akan datang serta menjadikan daya saing bagi perusahan dalam suatu industri.

Faizal (2004) mendefenisikan bahwa Institutional Ownership merupakan kepemilikan saham suatu perusahaan yang dimiliki oleh pihak diluar menajerial yang berfungsi sebagai pihak yang memonitoring perusahaan. Himmelberg, Hubbard, dan Palia (1999), mengatakan aktivitas monitoring tersbut diharapkan mampu menjamin kemakmuran bagi pemegang saham didalam perusahaan. Institutional Ownership berperan sebagai pengawas di dalam perusahaan akan berpengaruh dikarenakan besarnya jumlah investasi yang ditanam dalam pasar modal.

Horne dan Wachowicz (2000) mengatakan bahwa manajemen Working Capital merupakan komponen yang sangat penting dikarenakan mampu mempengaruhi likuiditas dan profitabilitas. Perusahaan dengan tingkat asset yang terlalu sedikit mungkin akan mengalami kekurangan dan kesulitas dalam menjaga kelancaran operasi. Eljelly (2004) Working Capital yang efisien yang melibatkan perencanaan dan pengendalian asset lancer dan liabilities denegan cara menghilangkan risiko ketidakmampuan untuk memenuhi kewajiban jangka pendek dan menghindari investasi yang berlebihan.

\section{METODOLOGI PENELITIAN}

Penelitian dilakukan menggunakan metode kuantitatif dan menggunakan desain penelitian konklusif deskriptif. Dalam penelitian ini bentuk data yang digunakan yakni data panel yang merupakan kombinasi dari Time Series dan Cross Section. Populasi dalam penelitian ini adalah perusahaan-perusahaan sektor properti dan real estate yang telah go public 
di BEI periode 2014-2018. Terdapat 39 daftar perusahaan industri sektor properti dan real estate yang telah go public di BEI periode 2014-2018. Variabel dependen yang digunakan yakni nilai perusahaan dan variabel independen yang digunakan yakni Leverage, Growth, Institutional Ownership dan Working Capital Turnover. Operasional variabel dapat dilihat pada table berikut:

Tabel 1

Operasional Variabel

\begin{tabular}{|c|c|c|c|}
\hline Variabel & Dimensi & Ukuran & Skala \\
\hline Firm Value & Tobin's Q & $\mathrm{Q}=\{($ Current Price X Total Share $)+$ Debt $\}:$ Total Aset & Rasio \\
\hline Leverage & DER & Total Debt/Total Equity & Rasio \\
\hline Growth & GRWT & Growth of Sales $=(\mathrm{S}(\mathrm{t})-\mathrm{S}(\mathrm{t}-1)) /(\mathrm{S}(\mathrm{t}-1))$ & Rasio \\
\hline $\begin{array}{c}\text { Institutional } \\
\text { Ownerships }\end{array}$ & IO & $\begin{array}{c}\text { Jumlah saham yang dimiliki institusi / jumlah saham } \\
\text { beredar }\end{array}$ & Rasio \\
\hline $\begin{array}{c}\text { Working Capital } \\
\text { Turnover }\end{array}$ & WCTO & WCTO=Sales/(Working Capital $)$ & Rasio \\
\hline
\end{tabular}

\section{HASIL PENELITIAN DAN KESIMPULAN}

Hasil pengujian yang dilakukan dalam penelitian ini dapat dilihat dalam penjaabran tabel dibawah ini:

Tabel 2

Hasil Statistik Deskriptif

\begin{tabular}{cccccc}
\hline & TBQ & DER & GRWT & INST & WCTO \\
\hline Mean & 1.159973 & 0.768899 & 0.110916 & 0.644804 & 0.623656 \\
\hline Median & 0.928300 & 0.612600 & 0.042600 & 0.700750 & 0.508300 \\
\hline Max. & 6.067600 & 3.701000 & 8.432700 & 0.988400 & 2.741800 \\
\hline Min. & 0.073800 & 0.034700 & -1.232000 & 0.161600 & 0.045000 \\
\hline Std. Dev. & 0.897611 & 0.582061 & 0.797081 & 0.204392 & 0.473221 \\
\hline Skewness & 2.274677 & 1.444558 & 7.046325 & -0.513096 & 1.821101 \\
\hline Kurtosis & 9.746768 & 6.369954 & 68.78009 & 2.355846 & 6.920941 \\
\hline Obs. & 190 & 190 & 190 & 190 & 190 \\
\hline
\end{tabular}

\section{Tabel 3}

Hasil Uji Multikolinearitas

\begin{tabular}{ccccc}
\hline & DER & GRWT & INST & WCTO \\
\hline DER & 1.000000 & 0.007133 & -0.151101 & 0.259006 \\
\hline GRWT & 0.007133 & 1.000000 & -0.065730 & 0.023608 \\
\hline INST & -0.151101 & -0.065730 & 1.000000 & 0.138071 \\
\hline WCTO & 0.259006 & 0.023608 & 0.138071 & 1.000000 \\
\hline
\end{tabular}

Dengan demikian dapat ditarik kesimpulan bahwa tidak terdapat multikolinearitas dikarenakan masing-masing variabel independen yakni Leverage (DER), Growth (GRWT), Institutional Ownership (INST), dan Working Capital Turnover (WCTO) memiliki tingkat korelasi antar variabel independen yang satu dengan lainnya lebih kecil dari 0.8 selain dari dirinya sendiri.

Tabel 4

Hasil Uji Regresi Data Panel

\begin{tabular}{lllll}
\hline Variable & Coefficient & Std. Error & t-Statistic & Prob. \\
\hline C & 1.823255 & 0.492976 & 3.698467 & 0.0004 \\
DER & -0.050911 & 0.116823 & -0.435792 & 0.6641 \\
GRWT & -0.018000 & 0.004758 & -3.783244 & 0.0003 \\
INST & $6.00 \mathrm{E}-05$ & $5.57 \mathrm{E}-06$ & 10.78199 & 0.0000 \\
R-squared & 0.206016 & & & \\
Adjusted R-squared & 0.188848 & & & \\
S.E. of regression & 0.808424 & & & \\
F-statistic & 12.00052 & & & \\
Prob(F-statistic) & 0.000000 & & & \\
\hline Sumber: Hasil Pengolahan & & & \\
\hline
\end{tabular}

Sumber: Hasil Pengolahan E-views. 
Dari hasil yang terangkum di dalam tabel 4 dapat dilihat bawha nilai Prob (F-Statistic) menunjukkan hasil $0.000000<0.05$ artinya Leverage (DER), Growth (GRWT), institutional ownership (INST), dan working capital turnover (WCTO) secara simultan memiliki pengaruh terhadap Firm Value. Adjusted R-squared diperolah hasil sebesar 0.188848 dan bernilai positif, atau apabila dipersenkan maka sama dengan $18.88 \%$. sehingga dapat disimpulakan bahwa Firm Value sebagai variabel independen dapat dijelaskan oleh variabel dependen yakni Leverage, Growth, institutional ownership dan working capital turnover dan sisanya sebesar $81.12 \%$ dapat dijelaskan oleh variabel lainnya. Hasil uji dari regresi data panel menunjukkan bahwa Leverage dan Institutional Ownership berdampak positif dan signifikan terhadap Firm Value sedangkan Growth dan Working Capital Turnover berdampak positif namun kurang signifikan terhadap Firm Value.

Pengujian data pada variabel Leverage menunjukkan bahwa Leverage berpengaruh secara positif dan signifikan terhadap Firm Value. Dimana, dapat dikatakan bahwa sejalan depan $\mathrm{H} 1$ yang telah disusun dengan tingkat keyakinan 95\%. Penelitian ini sejalan dengan yang penelitian yang dilakukan oleh Sulong et al. (2013), Obradovich \& Gill (2013) dan Black, Jang dan Kim (2003) yang menyatakan terdapat pengaruh positif dan signifikan antara Leverage dengan nilai perusahaan. Perusahaan juga harus memperhatikan dalam hal penggunaan hutang didalam perusahaan, dikarenakan apabila perusahaan melewati batas kemampuan perusahaan dalam penggunaan hutang maka akan membuat perushaaan akan mengurangi manfaat yang diterima dan terjadinya ketidak seimbangan dengan manfaaat yang diterima (Siahaan, 2013). Penggunaan hutang yang berlebihan dalam perusahaan apabila sedang mengalami kesusahaan perekonomiannya akan membuat perusahaan akan terjerumus kedalam kepailitan yang akan membuat perusahaan rugi besar dan bahkan bisa menutup usaha.

Pembahasan mengenai hasil pengujian pada variabel kedua yakni Growth yang menunjukkan bahwa Growth berpengaruh secara positif namun tidak signifikan terhadap Firm Value. Hasil ini tidak sejalan dengan hasil penelitian yang dilakukan oleh Sukaenah (2015), Cheng et al., (2010), Fista \& Dini (2017), dimana Growth berpengaruh positif signifikan terhadap Firm Value. Perbedaan akan hipotesis yang disusun dikarenakan, adanya pertumbuhan penjualan yang dihitung secara murni kenaikan penjualan bersih per tahun. Namun, tidak memperhitungkan atau mengurangi biaya-biaya yang ada didalam perusahaan seperti biaya operasional lainnya. Hal ini mengakibatkan peningkatan penjualan yang dialami perusahaan tidak mengidentifikasi adanya laba perusahaan yang meningkat apabila biaya operasional didalam perusahaan juga terhitung meningkat. Penelitian ini sejalan dengan penelitian yang dilakukan oleh Hansen dan Juniarti (2014).

Institutional Ownership yang menjunjukkan hasil berpengaruh secara positif dan signifikan terhadap Firm Value. Penelitian ini sejalan dengan yang penelitian yang dilakukan oleh Thanatawee (2014), El-Habashy (2019), Setiyono dan Devie (2017), Ameer (2012). Hal ini membuktikan bahwa Institutional ownership sebagai pihak ketiga memiliki peran penting di dalam perusahaan karena mengurangi agency conflict yang dapat merugikan perusahaan karena adanya perselisihan internal perusahaan. Manajer juga dalam penggunaan hutang dimonitor secara ketat dan optimal oleh pemegang saham esksternal agar tidak menggunakan secara berlebihan serta membantu mengurangi peningkatan agency cost yang mampu mendukung peningkatan nilai perusahaan.

Variabel keempat yakni Working Capital Turnover yang menunjukkan hasil pengujian data pada variabel tidak memiliki pengaruh secara positif namun tidak signifikan terhadap Firm Value. Hal ini sejalan dengan teori yang mengatakan bahwa working capital turnover yang tinggi mampu memperhitungkan tingkat efisiensi dan efektifitas dalam megelola dan menjalankan kegiatan operasional suatu perusahaan. Hal ini dikarenakan persediaan atau aktiva lancar yang dimiliki perusahaan property relatif lebih rendah dan mayoritas dari Working Capital Turnover perusahaan tidak efisien. Penelitian ini tidak sejalan dengan 
Hachiya (2005), Cumbie \& John (2017) dan Wibowo \& Eni (2018). Perbedaan penelitian juga didasarkan karena adanya perbedaan sampel perusahaan yang diteliti.

\section{SARAN}

Penelitian yang dilakukan ini masi terdapat banyak keterbatasan dimana hanya menggunakan satu proksi dalam perhitungan variabel. Peneliti juga dapat mengalasis dan menguji dengan menambahkan variabel moderasi yang mampu menjadi memperkuat atau memperlemah hubungan antar variabel independen terhadap variabel dependen dengan menggunakan periode dan sektor perusahaan yang berbeda dengan penelitian ini. Serta dapat menggunakan proksi berbeda atau menggunakan 2 proksi sekaligus dalam meneliti. Penelitan berikutnya juga bisa menambahkan variabel yang menjadi pemicu peningkatan nilai perusahaan yang lebih besar lagi.

\section{DAFTAR PUSTAKA}

Ameer, R. (2012). Impact of cash holdings and ownership concentration on firm valuation: Empirical evidence from Australia. Review of Accounting and Finance, 11(4).

Barton, S. L., Hill, N. C., \& Sundaran, S. (1989). An emprical test of stakeholder theory prediction of capital structure. Journey of the financial management association, spring ratio valution models. Journal of Finance \& Accounting, 26(3), 393-416.

Black, B. S., Jang, H. S., \& Kim, W.C. (2003). Does Corporate Governance Affect Firm Value? Evidence from Korea.Mitsui Life Symposium on Global Financial Markets.

Brigham, E. F., \& Houston, J. F. (2006). Dasar-dasar Manajemen Keuangan (Edisi Kesepuluh, Buku Satu). Jakarta: Penerbit Erlangga.

Cumbie, J. B., \& Donnellan, J. (2017). The impact of working capital components on firm value in US Firms. International Journal of Economics and Finance, 9(8).

El-Habashy, H. A. (2019). The effects of board and ownership structures on the performance of publicly listed companies in Egypt. Academy of Accounting and Financial Studies Journal, 23(1), 1-15.

Eljelly, A. (2004). Liquidity-profitability tradeoff: An empirical investigation in an emerging market. International Journal of Commerce and Management, 14(2), 48-61.

Faizal. (2004). Analisis agency costs, struktur kepemilikan dan mekanisme corporate governance. Simposium Nasional Akuntansi VII Denpasar Bali. 2-3 Desember.

Gitman, L. J. (2002). Principles of Managerial Finance (10 ${ }^{\text {th }}$ ed.). Pearson Education.

Hachiya, Q. L. T. (2005). Bank relations, cash goldings, and firm value: Evidence from Japan. Management Research News, 28(4).

Hansen \& Juniarti. (2014). Pengaruh family control, size, sales growth, dan leverage terhadap profitabilitas dan nilai perusahaan pada sektor perdagangan jasa. Business Accounting Reviews, 2(1), 2014.

Himmelberg, C. P., Hubbard, R. G., \& Palia, D. (1999). Understanding the determinants of managerial ownership and the link between ownership and performance. Journal of Financial Economics, 53, 353-384.

Khaliq, A., et.al. (2014). Identifying financial distress company: A case study of Malaysia's government linked companies (GLC). International Journal of Economics, Finance, and Management, 3(3), 141-150.

Obradovich, J., \& Gill, A. (2013). The impact of corporate governance and financial leverage on the value of American firms. International Research Journal of Finance and Economics (91).

Setiyono, M. A., \& Devie. (2017). Pengaruh institutional ownership terhadap firm value melalui dividend policy pada perusahaan yang terdaftar di Bursa Efek Indonesia periode 2013-2015. Business Accounting Review, 5(2), 553-564. 
Siahaan, F. O. (2013). The effect of good corporate governance mechanism, leverage, and firm size on firm value. GSTF Journal on Business Review (GBR), 2(4), 137-142.

Sukaenah. (2015). Pengaruh earning per share (EPS), ukuran perusahaan, profitabilitas, leverage, dan sales growth terhadap nilai perusahaan pada industri makanan dan minuman yang terdaftar di Bursa Efek Indonesia tahun 2008-2013. E-Jurnal Akuntansi Universitas Pandanaran Semarang.

Sulong, Z., Gardne, J. C., Hussin, A. H., Sanusi, Z. M., \& Jr, C. B. (2013). Managerial ownership, leverage and audit quality impact on firm performance: Evidence from The Malaysian ACE Market . Accounting and Taxation, V(1), 59-70.

Thanatawee, Y. (2014). Institutional ownership and firm value in Thailand. Asian Journal of Business and Accounting, 7(2).

Wibowo, S. S., \& Rohyati, E. (2018). The effect of working capital turnover and profitability of inventory turnover manufacturing companies listed in indonesia stock exchange. 